\title{
Evidências Geomorfológicas de Mudanças Ambientais na Baía Esperança, Península Antártica
}

\author{
Geomorphological Evidences of Environmental Changes \\ in Hope Bay, Antarctic Peninsula
}

\begin{abstract}
Rafaela Mattos Costa ${ }^{1} \varangle$ (D), Carina Petsch ${ }^{2} \bowtie$, Maria Eliza Sotille ${ }^{3} \varangle$, Katia Kellem da Rosa $4 \bowtie$
Jefferson Cardia Simões ${ }^{5} \bowtie$, Ulisses Franz Bremer ${ }^{\natural} \bowtie$, André Medeiros de Andrade ${ }^{7} \bowtie$
\end{abstract}

1 Universidade Federal do Rio grande do Sul, raffaellamattos@hotmail.com,
https://orcid.org/0000-0003-0496-7377
2 Universidade Federal do Rio Grande do Sul, carinapetsch@gmail.com
3 Universidade Federal do Rio Grande do Sul, sotille@gmail.com
${ }^{4}$ Universidade Federal do Rio Grande do Sul, katiakellem@gmail.com
5 Universidade Federal do Rio Grande do Sul, jefferson.simoes@ufrgs.br
6 Universidade Federal do Rio Grande do Sul,ulissesbremer@gmail.com
7 Universidade Federal do Rio Grande do Sul, andremedeirosbh@gmail.com

Resumo: Apresentam-se resultados acerca da geomorfologia dos ambientes proglaciais das geleiras Buenos Aires, Kenney e Flora, na Baía Esperança, Península Antártica, entre as coordenadas $63^{\circ} 23^{\prime} \mathrm{S}$ e $63^{\circ} 26^{\prime} \mathrm{S}$ de latitude e $56^{\circ} 8^{\prime} \mathrm{O}$ e $57^{\circ} 4^{\prime} \mathrm{O}$ de longitude. Foram realizadas análises sedimentares, granulométrica e morfoscópica, de 15 amostras coletadas em 2017 para a identificação das feições geomorfológicas deposicionais e posterior mapeamento geomorfológico. Foram delimitadas as frentes das geleiras a partir de imagens Sentinel-2 e Quickbird de 1988, 2008 e 2017 utilizando o software ArcGIS® para identificar a cronologia das formas. O predomínio de grãos grossos, a baixa seleção e os altos valores do índice $\mathrm{C}_{40} \mathrm{em}$ todas as amostras indicam modificação por processos erosivos em ambiente supraglacial e/ou pouca distância de transporte após o arrancamento do substrato e fraturamento dos grãos por intemperismo físico pós-deposicional. A reconstrução da paisagem holocênica da Baía Esperança indica geleiras com dezenas de metros de avanço em relação à frente atual, durante a Pequena Idade do Gelo (PIG). O mapeamento geomorfológico e análises realizadas evidenciam recentes mudanças ambientais no sistema proglacial, com formação de morainas hummocky indicando a retração/estabilização das geleiras na PIG, além de morainas de recessão recentes, que na geleira Buenos Aires predominam na fase 2008-2017, na geleira Flora no período 1988-2008 e na geleira Kenney no período 2008-2017.

Palavras-chave: Geomorfologia Glacial; Geleiras; Holoceno Superior; Sedimentologia; Mapeamento.

Abstract: A geomorphological interpretation of the glacial geomorphology of the proglacial environments of the Buenos Aires, Kenney and Flora glaciers in Hope Bay, Antarctica, between the coordinates $63^{\circ} 23^{\prime} S$ and $63^{\circ} 26^{\prime} \mathrm{S}$ latitude and $56^{\circ} 8^{\prime} \mathrm{W}$ and $57^{\circ} 4^{\prime} \mathrm{W}$ longitude. Sedimentary, granulometric and morphological analyzes were carried out on 15 samples collected in 2017 for the identification of depositional geomorphological features and subsequent geomorphological mapping. The glacier fronts were delineated from Sentinel-2 and Quickbird images of 1988, 2008 and 2017 using the ArcGIS® software to identify the landforms chronology of the shapes. The higher number of coarse grains, low selection, and high values of $C_{40}$ in all samples indicate modification by erosive processes in supraglacial environment and/or transport distance after substrate quarrying process and grain fracturing by post-depositional physical weathering. The reconstruction of the Hope Bay's Holocene landscape of indicates glaciers with tens of meters of advance compared to the current front during the Little Ice Age (LIA). The geomorphological mapping and sedimentary analyzes showed recent environmental changes in the proglacial system, with formation of hummocky moraines indicating the retreat/stabilization of the glaciers in the LIA. Furthermore, they set 
evidences of recent recession moraines, which prevail in the Buenos Aires Glacier predominate in the 20082017 phase, on the Flora Glacier in 1988-2008 period and the Kenney Glacier in the 2008-2017 period.

Keywords: Glacial Geomorphology; Glaciers; Upper Holocene; Sedimentology; Mapping.

\section{Introdução}

Os ambientes glaciais apresentam indicadores sensíveis às mudanças climáticas e a análise da evolução das áreas livres de gelo é relevante para melhor entendimento das respostas da dinâmica glacial a estas mudanças (GLASSER e HAMBREY, 2002; BOULTON, 1967; ADAM e KNIGHT, 2003; COWIE et al. 2014; CARRIVICK, 2015). A maioria das geleiras apresentam fortes variações sazonais de aporte de água de degelo, além de variações anuais na ablação de superfície da geleira devido a alterações na radiação solar e na temperatura do ar (BENN e EVANS, 1998).

Os processos de liberação da água armazenada no sistema glacial para o proglacial dependem da variabilidade da descarga de água de degelo. Com a retração muitas geleiras têm a estocagem hídrica reduzida e transferem mais água e sedimentos em suspensão para os canais de fusão, lagos e ambiente glaciomarinho. Esses sedimentos contribuem na formação de feições proglaciais da geleira (CUFFEY e PATERSON, 2014). A dinâmica de degelo das geleiras é importante para relacionar transporte sedimentar e formação de geoformas deposicionais relacionadas à dinâmica das geleiras (FOUNTAIN e WALDER, 1998).

O ambiente proglacial, formado pela recente retração glacial, gera depósitos morâinicos, flutings e éskers, resultantes de ambientes glaciofluviais, glaciolacustres e glaciomarinhos. As margens de geleiras são assim marcadas por grande variedade de feições deposicionais produzidas pelas interações complexas de processos glaciogênicos e paraglaciais (BENN e EVANS, 2010). A própria zona proglacial modifica-se em sua área de acordo com a variação da frente da geleira (GOUDIE, 2004).

As geleiras são sistemas sensíveis às mudanças climáticas, apresentando variações em extensão e volume em resposta às mudanças de temperatura do ar e precipitação de neve, de modo que as flutuações de geleiras do passado e presente servem como uma importante fonte de informação sobre o funcionamento e variabilidade do sistema climático global (BENN e EVANS, 2010; CUFFEY e PATERSON, 2014). A identificação geomorfológica glacial é relevante para interpretar os processos subglaciais e inferir a dinâmica de avanço e recuo da geleira e, assim, reconstruir a evolução do ambiente de deglaciação (BENNETT e GLASSER, 1996; GLASSER e HAMBREY, 2002).

A análise granulométrica fornece a distribuição do tamanho dos grãos das amostras, fortemente influenciada pela litologia original e também pela história dos sedimentos. Processos pós-deposicionais também podem modificar a distribuição original do tamanho dos grãos de um depósito (LEWIS e MCCONCHIE, 1994). A análise morfoscópica possibilita a identificação dos ambientes sedimentares, com como a reconstrução da história de transporte, erosão e deposição dos depósitos glaciais (BENN e BALLANTYNE, 1994).

Com o recente processo de retração de geleiras na região da Península Antártica e ilhas adjacentes, tornase importante o monitoramento das respostas da dinâmica glacial e proglacial e as interligações existentes. Dentro desta temática, avaliou-se a evolução da paisagem holocênica da Baía Esperança, Antártica, através da caracterização sedimentar e do mapeamento das principais feições geomorfológicas proglaciais das geleiras Flora, Kenney e Buenos Aires, inédito para essas áreas.

\section{Caracterização da Área de Estudo}

A Baía Esperança (Figura 1) localiza-se no extremo oriental da Península Trinity (norte da Península Antártica) entre as latitudes $63^{\circ} 14^{\prime}$ e $63^{\circ} 39^{\prime} \mathrm{S}$ e longitudes $56^{\circ} 59^{\prime}$ e $57^{\circ} 37^{\prime} \mathrm{O}$, e está incluída na Antártica Marítima (OVSTEDAL e SMITH, 2001). O presente estudo apresenta resultados acerca da geomorfologia de ambientes proglaciais das geleiras Buenos Aires, Kenney e Flora.

De acordo com a classificação de Köppen, a região enquadra-se no clima $\mathrm{EF}$ (polar). As condições locais indicadas pela Base Esperança apontam temperaturas médias máximas entre $2,6^{\circ} \mathrm{C}$ e $3,2^{\circ} \mathrm{C}$ durante o verão (dezembro, janeiro e fevereiro). Nesse período a temperatura pode chegar a $17,5^{\circ} \mathrm{C}$, como aconteceu em 2015. Os meses menos ventosos são dezembro e janeiro $( \pm 20 \mathrm{~km} / \mathrm{h})$, em comparação com maio, julho, agosto e setembro, quando os ventos são mais fortes $(>30 \mathrm{~km} / \mathrm{h})$. Eventualmente ventos catabáticos da geleira local são registrados (Serviço Meteorológico Nacional, Argentina). 
Quanto à geologia, a Baía Esperança mostra uma sequência de rochas sedimentares (Formação Monte Flora - Jurássico), metassedimentares (Grupo Península Trinity - Permiano-Triássico) e vulcânicas (Grupo Península Antártida - Mesozóico) (BIRKENMAJER, 1993; DEL VALLE et al. 2001). Para o reconhecimento dos solos, Schaefer et al. (2015) mapearam terraços marinhos, afloramentos rochosos, morainas, talus e cones na Baía Esperança.

Embora a Baía Esperança tenha uma das maiores colônias de pinguim-de-adélia (Pygoscelisadeliae) da Península Antártica, ocorrendo ornitogênese e consequente intemperização química (PEREIRA et al. 2013), os solos, por se desenvolverem em um ambiente mais frio e seco, quando comparados com os solos das ilhas Shetland do Sul, têm menor desenvolvimento da vegetação e, consequentemente, menor grau de intemperismo das rochas. Assim, a flora nessa área é escassa e distribuída em pequenas manchas irregulares, predominantemente composta por comunidades de criptógamas, como musgos, líquens e algas (SMITH 1984; OVSTEDAL e SMITH, 2001; CONVEY, 2013).

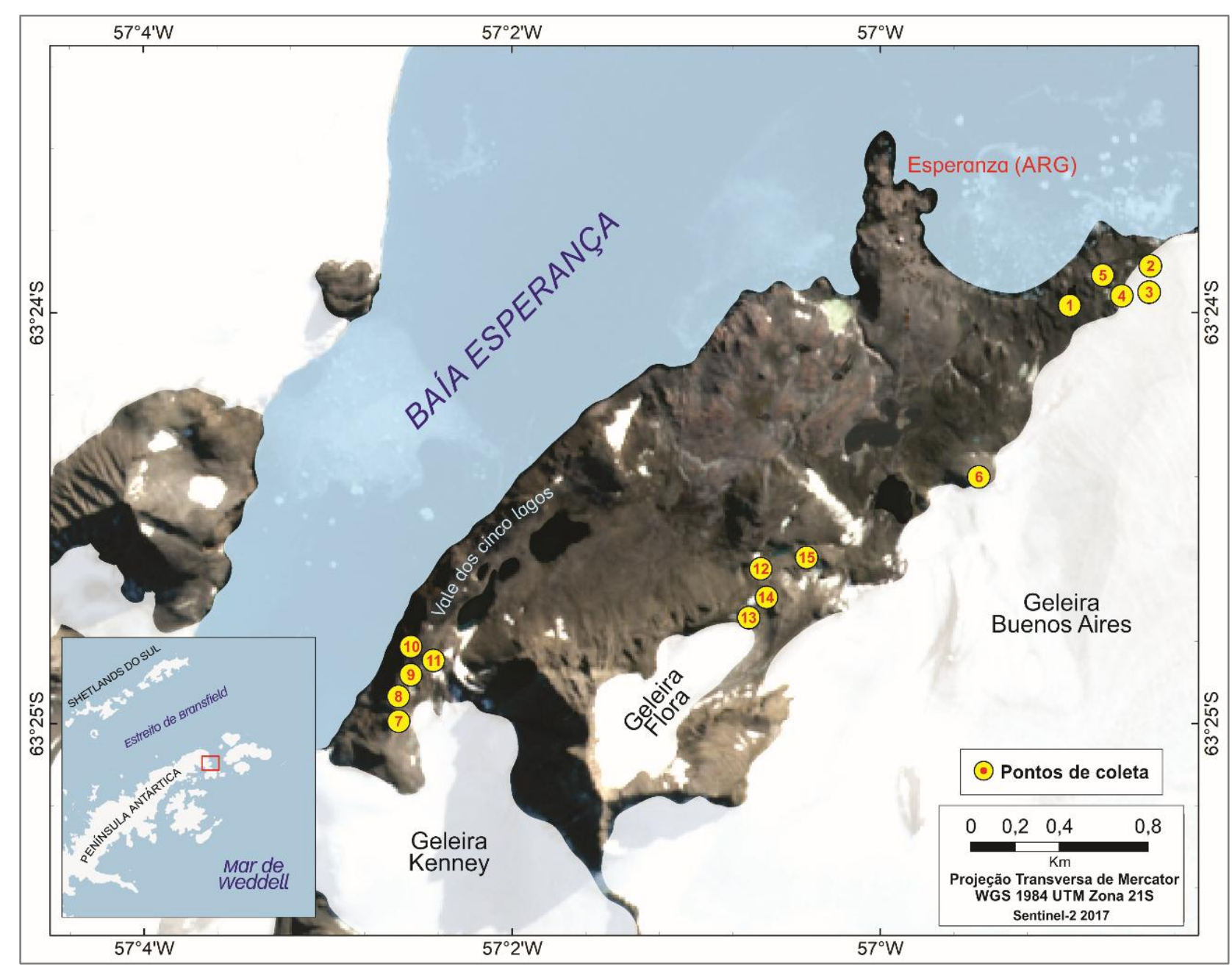

Figura 1: Localização da Península Antártica no continente antártico (A) e da Baía Esperança na Península Antártica (B). Em amarelo, os pontos de coleta de sedimentos na área de estudo (C).

\section{Materiais e Métodos}

\subsection{Análise Sedimentar}

A coleta dos sedimentos foi realizada durante expedição realizada em janeiro de 2017. As amostras foram coletadas com uma pá, evitando o material intemperizado e na quantidade aproximada de $300 \mathrm{~g}$. Em cada local de coleta foram demarcados pontos de controle de GPS (elevação e coordenadas), fotografia com escala e observação do ambiente de entorno como orientação, tamanho do depósito e matriz. A análise dos sedimentos determina a distribuição granulométrica e as características morfoscópicas e auxilia na identificação das formas, método utilizado também por Petsch (2018) e Rosa (2008) para as ilhas Shetland do Sul - Antártica. 


\subsection{Análise Granulométrica}

O processo se iniciou com a secagem das amostras, seguindo da desagregação preliminar com o uso de um almofariz e pistilo. Posteriormente, as amostras foram submetidas à separação em sedimentos finos e grossos através de um conjunto de peneiras com malha decrescente até o limite de $62 \mu \mathrm{m}$ (escala Wentworth e Stokes) pelo processo seco. Assim, foi realizada a separação de acordo com as classes texturais e, em seguida, a pesagem por classe.

Os dados foram processados usando o software GRADISTAT ${ }^{\circledR}$, obtendo-se o grupo textural da amostra, a distribuição percentual das classes texturais dos sedimentos segundo a escala de Wentworth (1992) e a classificação do comportamento (unimodal, bimodal ou trimodal).

\subsection{Análise Morfoscópica}

A análise foi realizada em 100 grãos das três classes granulométricas de maior intervalo de cada amostra (maior que $1400 \mu \mathrm{m}$ ). Para a análise do grau de arredondamento (presença ou ausência de angularidades na superfície externa) utilizou-se tabela de comparação de Krumbein (1941). A textura superficial (ornamentação das faces dos grãos e presença ou ausência de brilho) das amostras foi determinada através da classificação de Bigarella (1946). Além disso, foi examinada a presença de estrias.

A forma do clasto foi definida pela dimensão relativa dos três eixos ortogonais, chamados a (maior), b (intermediário), e c (menor) (HUBBARD e GLASSER, 2005). O índice $\mathrm{C}_{40}$ (\% de clastos cujo eixo c/a é < 0.4 ) foi determinado a partir do software TRIPLOT.

\subsection{Mapeamento Geomorfológico Atual da Zona Proglacial}

O mapeamento geomorfológico dos ambientes e geoformas deposicionais, proglacial e marginal ao gelo, foi realizado para feições de mesoescala. As feições foram identificadas pela análise de registros sedimentares, por interpretação geomorfológica em campo e pela análise de imagens Sentinel-2, multiespectral, com $10 \mathrm{~m}$ de resolução espacial. A imagem foi georreferenciada utilizando a base cartográfica da Antarctica Digital Database (http://www.add.scar.org/).

Para o mapeamento geomorfológico, foi criada uma chave de interpretação para definição e identificação das formas baseada em Glasser et al. (2005), Hubbard e Glasser (2005), Smith e Clark (2005) e Gustavsson et al. (2006) (Tabela 1). Foram definidas as zonas marginal ao gelo e distal ao gelo de acordo com Menzies (2002).

Tabela 1: Chave de interpretação para definição e identificação das formas.

\begin{tabular}{|c|c|c|c|}
\hline $\begin{array}{c}\text { Feição } \\
\text { mapeada }\end{array}$ & Perfil & $\begin{array}{c}\text { Disposição espacial e } \\
\text { morfologia }\end{array}$ & $\begin{array}{c}\text { Posiçãa em } \\
\text { relação à geleira }\end{array}$ \\
\hline $\begin{array}{c}\text { Cristas } \\
\text { morâinicas } \\
\text { de avanço }\end{array}$ & Geleira & $\begin{array}{l}\text { Perpendicular à direção de } \\
\text { fluxo, mais externa, perfil } \\
\text { assimétrico e íngreme na face } \\
\text { proximal ao gelo }\end{array}$ & \multirow{3}{*}{$\begin{array}{l}\text { Zonas frontal e } \\
\text { latero-frontal }\end{array}$} \\
\hline $\begin{array}{c}\text { Cristas } \\
\text { morâinicas } \\
\text { de recessão }\end{array}$ & Geleira $\quad$ Feição & $\begin{array}{l}\text { Perpendicular à direção de } \\
\text { fluxo, perfil simétrico }\end{array}$ & \\
\hline $\begin{array}{c}\text { Cristas } \\
\text { morâinicas } \\
\text { de avanço/ } \\
\text { estagnação } \\
\text { do tipo } \\
\text { hummocky }\end{array}$ & Geleira & $\begin{array}{l}\text { Perpendicular à direção de } \\
\text { fluxo, cristas descontínuas, } \\
\text { forma em montículos, a } \\
\text { margem glacial é dificilmente } \\
\text { reconhecida }\end{array}$ & \\
\hline
\end{tabular}

\subsection{Evolução da paisagem holôcenica}

A reconstrução da evolução do ambiente proglacial e a cronologia das formas deposicionais foram obtidas com o mapeamento das posições frontais das geleiras Buenos Aires, Kenney e Flora a partir de imagens Sentinel-2 e Quickbird de 1988, 2008 e 2017 utilizando o software ArcGIS®. 


\section{Resultados}

\subsection{Caracterização Sedimentar das Zonas Proglaciais das Geleiras}

\subsubsection{Caracterização Sedimentar da Zona Proglacial da Geleira Buenos Aires}

A amostra 1 está na zona proglacial distal, a cerca de $50 \mathrm{~m}$ da frente atual da geleira e se classifica como moraina de recessão. A presença de maior quantidade de areia nessa amostra e o baixo índice $\mathrm{C}_{40}(36 \%)$ (Figura 2) indicam que o material está mais retrabalhado do que as amostras 2 e 3, que ainda estão em na zona proglacial marginal (frente da geleira).

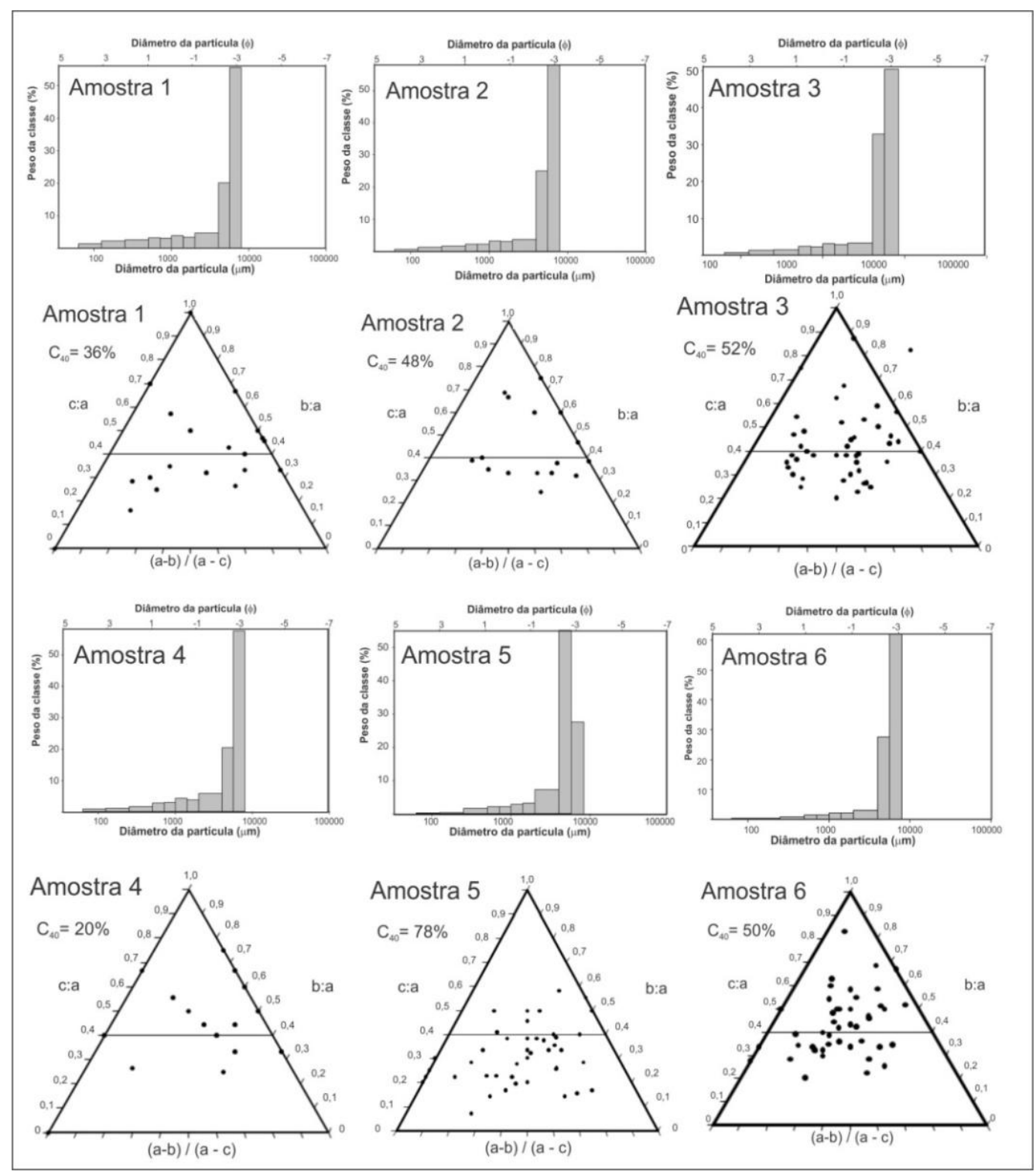

Figura 2: Análise granulométrica e morfoscópica das amostras coletadas no sector proglacial da geleira Buenos Aires.

As amostras 2 e 3 são, provavelmente, transportadas passivamente (na zona supraglacial), com pouca distância de transporte e estão relacionadas com processos de empurrão e compressão, pela diminuição da espessura em setores frontais. A amostra 5, apesar de estar mais distante da margem da geleira que as amostras 2 e 3, preserva características semelhantes a essas e pode-se afirmar que também foi transportada passivamente. Essas amostras (2, 3 e 5) estão em ambiente marginal ao gelo, onde há predomínio de sedimentos grossos, resultando numa distribuição unimodal. $\mathrm{O}$ arredondamento predomina em angular, a textura superficial em sacaróide fosca e o índice $\mathrm{C}_{40}$ é alto (Figura 2).

A amostra 4 (Figura 2) também está no ambiente marginal ao gelo, mas tem características de transporte ativo (através da zona subglacial - base da geleira). Predomina o seixo/cascalho $(81,1 \%$ ) como classe textural, mas há uma porcentagem de partículas finas (18,3\% de areia e 0,3\% de silte/argila), indicando quebra dos grãos. Além disso, os grãos são mais esféricos (índice $\mathrm{C}_{40}$ de $20 \%$ ) e arredondados (86\% de angular e $14 \%$ de subangular). 
A amostra 6 foi coletada em uma moraina hummocky e as características sedimentares evidenciam pouco retrabalhamento dos grãos: há um baixo selecionamento (91,3\% de seixo/cascalho e $8,7 \%$ de areia) e uma tendência para grãos esféricos $\left(\mathrm{C}_{40}\right.$ de $\left.50 \%\right)$ (Figura 2). Além disso, a totalidade dos grãos foi classificada como angular e sacaróide fosca.

\subsubsection{Caracterização Sedimentar da Zona Proglacial da Geleira Kenney}

As amostras 7 e 8 estão localizadas muito próximas, no ambiente marginal ao gelo, onde há morainas com 5-10 m de altura média, com cobertura superficial formada quase totalmente por grandes blocos rochosos. Indicam um processo de transição para uma área proglacial distal, com material mais retrabalhado, arredondamento predominante em angular e valores de $\mathrm{C}_{40}$ de $62 \%$ e $68 \%$, respectivamente (Figura 3). A amostra 9 foi coletada em uma moraina do tipo hummocky, que está na zona frontal atual da geleira. A distribuição percentual das classes texturais indica comportamento bimodal $(71,1 \%$ de seixo/cascalho e $28,9 \%$ de areia), evidenciando quebra dos grãos. O índice $\mathrm{C}_{40}$ é de $52 \%$, ou seja, os grãos são imaturos mais alongados e menos esféricos - sugerindo transporte passivo (Figura 3).

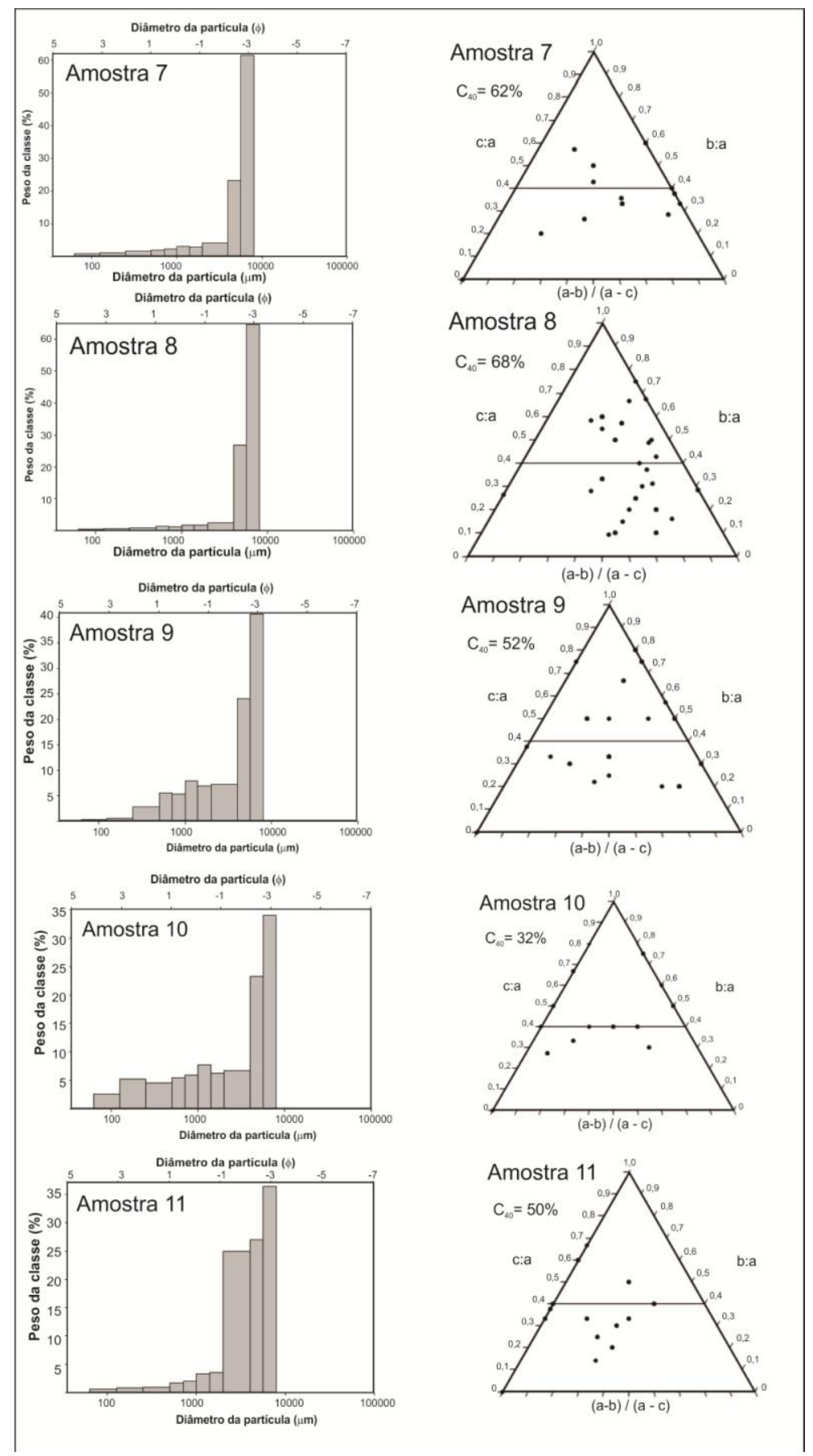

Figura 3: Análise sedimentar das amostras 7, 8, 9, 10 e 11, coletadas no sector proglacial da geleira Kenney. 
A amostra 10, coletada em uma crista morâinica de avanço, está em um ambiente em transição de proglacial para periglacial. Assim, o material está mais retrabalhado: o grupo textural foi classificado como seixo/cascalho/arenoso, a distribuição é trimodal (58\% de seixo/cascalho, $40 \%$ de areia e $1,7 \%$ de silte/argila), o arredondamento divide-se em angular (56\%) e subangular (44), a textura superficial é sacaróide fosca e o índice $\mathrm{C}_{40}$ é baixo (36\%) (Figura 3). O comportamento da amostra 11 (Figura 3), apesar de ser unimodal, é moderadamente selecionado, pois $88 \%$ da amostra é de seixo/cascalho e $12 \%$ é de areia. Ainda assim, o grupo textural foi classificado como seixo/cascalho.

\subsubsection{Caracterização Sedimentar da Zona Proglacial da Geleira Flora}

A amostra 12 (Figura 4) possui maior quantidade de areia $(3,8 \%)$ em relação às demais, e possui um valor considerável de grãos subangulares (20\%) e mamelonados foscos (14\%). As amostras 13 e 14 (Figura 4) estão localizadas muito próximas, no ambiente marginal ao gelo, e suas características sedimentares são semelhantes: predominância do seixo/cascalho como classe textural (97,7\% e 93,7\%, respectivamente), do arredondamento angular (96\% e $100 \%$, respectivamente) e da textura superficial sacaroide fosca (98\%). As duas amostras estão na margem da geleira, no entanto, o índice $\mathrm{C}_{40}$ é mais alto para a amostra 13 (62\%) quando comparado com o da amostra 14 (38\%), indicando maior retrabalhamento por conta da maior distância de transporte.

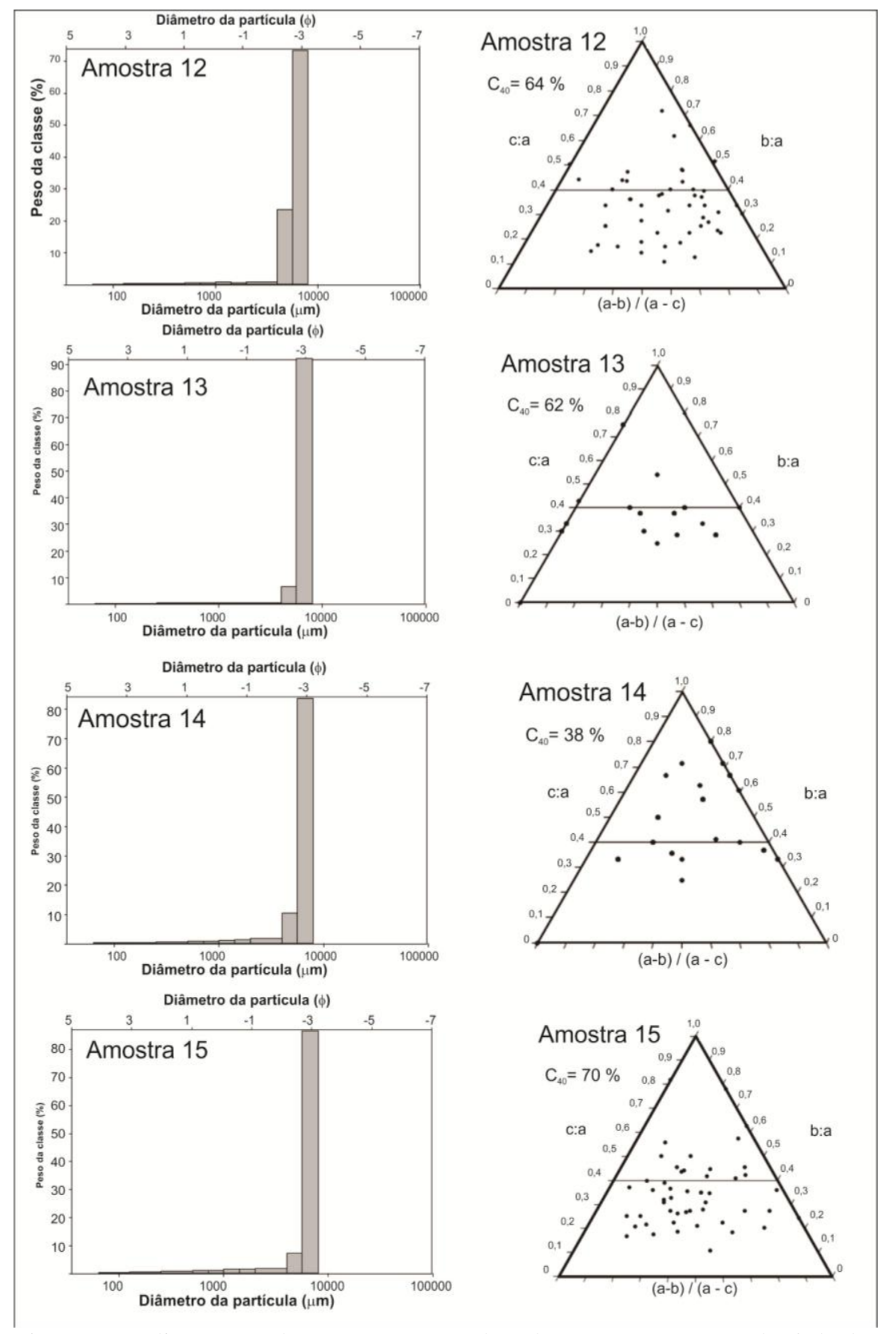

Figura 4: Caracterização sedimentar das amostras coletadas no setor proglacial da geleira Flora. As amostras têm predominância de seixo/cascalho e valores altos de $\mathrm{C}_{40}$. 
A amostra 15 (Figura 4) foi coletada em uma moraina hummocky. As características sedimentares evidenciam que o retrabalhamento dos grãos é muito reduzido: há totalidade de seixo/cascalho, grãos angulares e de textura mamelonada fosca. $\mathrm{O}$ alto índice $\mathrm{C}_{40}$ e todas as demais características evidenciam o maior alongamento e menor esfericidade dos grãos.

De forma geral, os valores do índice $\mathrm{C}_{40}$ (\% de clastos cujo eixo c/a é < 0.4$)$ considerados elevados (igual ou $>50 \%)$ indicam grãos mais alongados, enquanto valores considerados baixos $(<50 \%)$ indicam grãos mais esféricos. Das quinze amostras analisadas, somente quatro (amostras 1, 4, 10 e 14) apresentam valores do índice $\mathrm{C}_{40}$ baixos, ou seja, com tendência para grãos mais esféricos (Tabela 2).

Tabela 2: Análises granulométricas e morfoscópicas das amostras de sedimentos dos sectores proglaciais das geleiras Buenos Aires, Kenney e Flora, Baía Esperança, Antártica.

\begin{tabular}{|c|c|c|c|c|c|c|c|}
\hline & Amostra & $\begin{array}{l}\text { Grupo } \\
\text { textural }\end{array}$ & $\begin{array}{l}\text { Tipo da } \\
\text { amostra }\end{array}$ & $\begin{array}{l}\text { Distribuição \% } \\
\text { classes texturais }\end{array}$ & Arredondamento & $\begin{array}{c}\text { Textura } \\
\text { Superficial }\end{array}$ & C40 \\
\hline \multirow{6}{*}{ 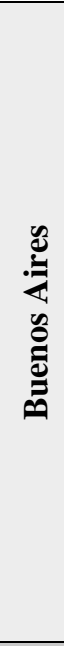 } & 1 & $\begin{array}{c}\text { Areia/ } \\
\text { Seixo/cascalho }\end{array}$ & Unimodal & $\begin{array}{c}75,5 \% \text { seixo/cascalho; } \\
23,6 \% \text { areia; } \\
0,9 \% \text { silte/argila } \\
\end{array}$ & $\begin{array}{l}\text { A }(92 \%) \\
\text { SA }(6 \%) ; \\
\text { SR }(2 \%)\end{array}$ & $\begin{array}{l}\mathrm{SF}(98 \%) \\
\operatorname{MF}(2 \%)\end{array}$ & $36 \%$ \\
\hline & 2 & Seixo/cascalho & Unimodal & $\begin{array}{c}83,3 \% \text { seixo/cascalho; } \\
16,1 \% \text { areia; } \\
0,6 \% \text { silte/argila }\end{array}$ & $\begin{array}{l}\text { A }(96 \%) \\
\text { SA }(4 \%)\end{array}$ & SF (100\%) & $50 \%$ \\
\hline & 3 & Seixo/cascalho & Unimodal & $\begin{array}{c}84,8 \% \text { seixo/cascalho; } \\
15,2 \% \text { areia; }\end{array}$ & $\begin{array}{l}\text { A }(88 \%) \\
\text { SA }(12 \%)\end{array}$ & $\begin{array}{l}\text { SF (80\%); } \\
\text { MF (20\%) }\end{array}$ & $54 \%$ \\
\hline & 4 & Seixo/cascalho & Unimodal & $\begin{array}{c}81,1 \% \text { seixo/cascalho; } \\
18,3 \% \text { areia; } \\
0,6 \% \text { silte/argila }\end{array}$ & $\begin{array}{l}\text { A }(86 \%) \\
\text { SA }(14 \%)\end{array}$ & $\begin{array}{l}\mathrm{SF}(94 \%) ; \\
\mathrm{MF}(6 \%)\end{array}$ & $20 \%$ \\
\hline & 5 & Seixo/cascalho & Unimodal & $\begin{array}{c}\text { 90,5\% seixo/cascalho; } \\
\text { 9,5\% areia; }\end{array}$ & $\begin{array}{l}\text { A }(90 \%) \\
\text { SA }(10 \%)\end{array}$ & $\begin{array}{l}\mathrm{SF}(96 \%) \\
\mathrm{MF}(4 \%)\end{array}$ & $78 \%$ \\
\hline & 6 & Seixo/cascalho & Unimodal & $\begin{array}{c}\text { 91,3\% seixo/cascalho; } \\
\text { 8,7\% areia; }\end{array}$ & A $(100 \%)$ & $\mathrm{SF}(100 \%)$ & $50 \%$ \\
\hline \multirow{5}{*}{ 离 } & 7 & Seixo/cascalho & Unimodal & $\begin{array}{c}85,1 \% \text { seixo/cascalho; } \\
14 \% \text { areia; } \\
0,9 \% \text { silte/argila }\end{array}$ & $\begin{array}{l}\text { A }(96 \%) \\
\text { SA }(4 \%)\end{array}$ & SF (100\%) & $62 \%$ \\
\hline & 8 & Seixo/cascalho & Unimodal & $\begin{array}{c}\text { 91,1\% seixo/cascalho; } \\
8,4 \% \text { areia; } \\
0,5 \% \text { silte/argila }\end{array}$ & A $(100 \%)$ & SF (100\%) & $68 \%$ \\
\hline & 9 & $\begin{array}{c}\text { Seixo/cascalho } \\
\text { /arenoso }\end{array}$ & Bimodal & $\begin{array}{c}71,1 \% \text { seixo/cascalho; } \\
28,9 \% \text { areia; }\end{array}$ & $\begin{array}{l}\text { A }(92 \%) ; \\
\text { SA }(8 \%)\end{array}$ & SF $(100 \%)$ & $52 \%$ \\
\hline & 10 & $\begin{array}{c}\text { Seixo/cascalho } \\
\text { /arenoso }\end{array}$ & Trimodal & $\begin{array}{c}58 \% \text { seixo/cascalho; } \\
40 \% \text { areia; } \\
1,7 \% \text { silte/argila }\end{array}$ & $\begin{array}{l}\text { A }(56 \%) \\
\text { SA }(44 \%)\end{array}$ & $\mathrm{SF}(100 \%)$ & $32 \%$ \\
\hline & 11 & Seixo/cascalho & Unimodal & $\begin{array}{c}88 \% \text { seixo/cascalho; } \\
11,5 \% \text { areia; } \\
0,4 \% \text { silte/argila }\end{array}$ & $\begin{array}{l}\text { A }(94 \%) \\
\text { SA }(6 \%)\end{array}$ & SF $(100 \%)$ & $50 \%$ \\
\hline \multirow{4}{*}{$\frac{\pi}{a}$} & 12 & Seixo/cascalho & Unimodal. & $\begin{array}{c}96,2 \% \text { seixo/cascalho; } \\
3,8 \% \text { silte/argila }\end{array}$ & $\begin{array}{l}\text { A (80\%); } \\
\text { SA (20\%) }\end{array}$ & $\begin{array}{l}\text { SF (86\%); } \\
\text { MF (14\%) }\end{array}$ & $64 \%$ \\
\hline & 13 & Seixo/cascalho & Unimodal & $\begin{array}{c}97,7 \% \text { seixo/cascalho; } \\
2,1 \% \text { areia; } \\
0,1 \% \text { silte/argila } \\
\end{array}$ & $\begin{array}{l}\text { A }(96 \%) \\
\text { SA }(4 \%)\end{array}$ & $\begin{array}{l}\mathrm{SF}(98 \%) \\
\operatorname{MF}(2 \%)\end{array}$ & $62 \%$ \\
\hline & 14 & Seixo/cascalho & Unimodal & $\begin{array}{c}93,7 \% \text { seixo/cascalho; } \\
6,1 \% \text { areia; } \\
0,2 \% \text { silte/argila }\end{array}$ & A $(100 \%)$ & $\begin{array}{l}\mathrm{SF}(98 \%) \\
\operatorname{MF}(2 \%)\end{array}$ & $38 \%$ \\
\hline & 15 & Seixo/cascalho & Unimodal & $100 \%$ seixo/cascalho & $\mathrm{A}(100 \%)$ & SF $(100 \%)$ & $70 \%$ \\
\hline
\end{tabular}

Abreviaturas: A: angular; SA: subangular; SR: subarredondado; SF: sacaroide fosco; MF: mamelonado fosco.

\subsection{Evolução Holocênica e Mapeamento Geomorfológico Proglacial}

Quanto a evidências do avanço recente da geleira Buenos Aires, há o pavimento estriado encontrado a 20 $\mathrm{m}$ da frente da geleira atual (Figura 5-B). Durante o seu avanço no Holoceno, a geleira Buenos Aires 
provavelmente atingiu o mar, ficando ancorada na proeminência próxima à Base Esperança, pois não há uma crista morâinica de avanço bem delimitada, somente várias feições de retração e reavanços.

A identificação das flutuações das geleiras entre 1988 a 2017 evidencia uma perda de $1,28 \mathrm{~km}^{2}$ de área no total. Entre os anos de 1988 e 2008 a perda foi de $0,89 \mathrm{~km}^{2}$ e entre os anos de 2008 a 2018 de $0,39 \mathrm{~km}^{2}$ (Figura 5).

A crista morâinica de avanço (amostra 10), os lagos do Vale dos Cinco Lagos, uma crista morâinica de recessão e a amostra 11, presentes na área proglacial da geleira Kenney, possuem sua gênese associada ao período entre a PIG e 1988, tal como as morainas hummocky da geleira Flora (amostras 12 e 15) e da geleira Buenos Aires (amostra 6, Figura 5-C).

Entre os anos 1988 e 2008 a perda de área das geleiras foi de $0,89 \mathrm{~km}^{2}$. Formaram-se na área proglacial da geleira Kenney feições como a moraina hummocky (amostra 9) ancorada em um lago, também formado nesse período. Ressalta-se que essa moraina pode ter sido formada por processos de avanço durante a PIG e exposta com a retração da geleira Kenney entre 1988 e 2008. Formou-se uma crista morâinica de recessão (amostra 13) na área proglacial da geleira Flora e o pavimento estriado encontrado a $20 \mathrm{~m}$ da frente da geleira Buenos Aires atual (Figura 3-B).

No período entre os anos de 2008 e 2017 a perda de área das geleiras foi de 0,39 $\mathrm{km}^{2}$. Formaram-se morainas de recessão (amostras 7 e 8) na área proglacial da geleira Kenney, ambiente com material pouco retrabalhado e cobertura superficial formada quase totalmente por grandes blocos rochosos, provenientes de queda do Monte Flora. (Figura 5-F). Na área proglacial da geleira Buenos Aires também se formaram morainas de recessão (amostras 2 a 5).

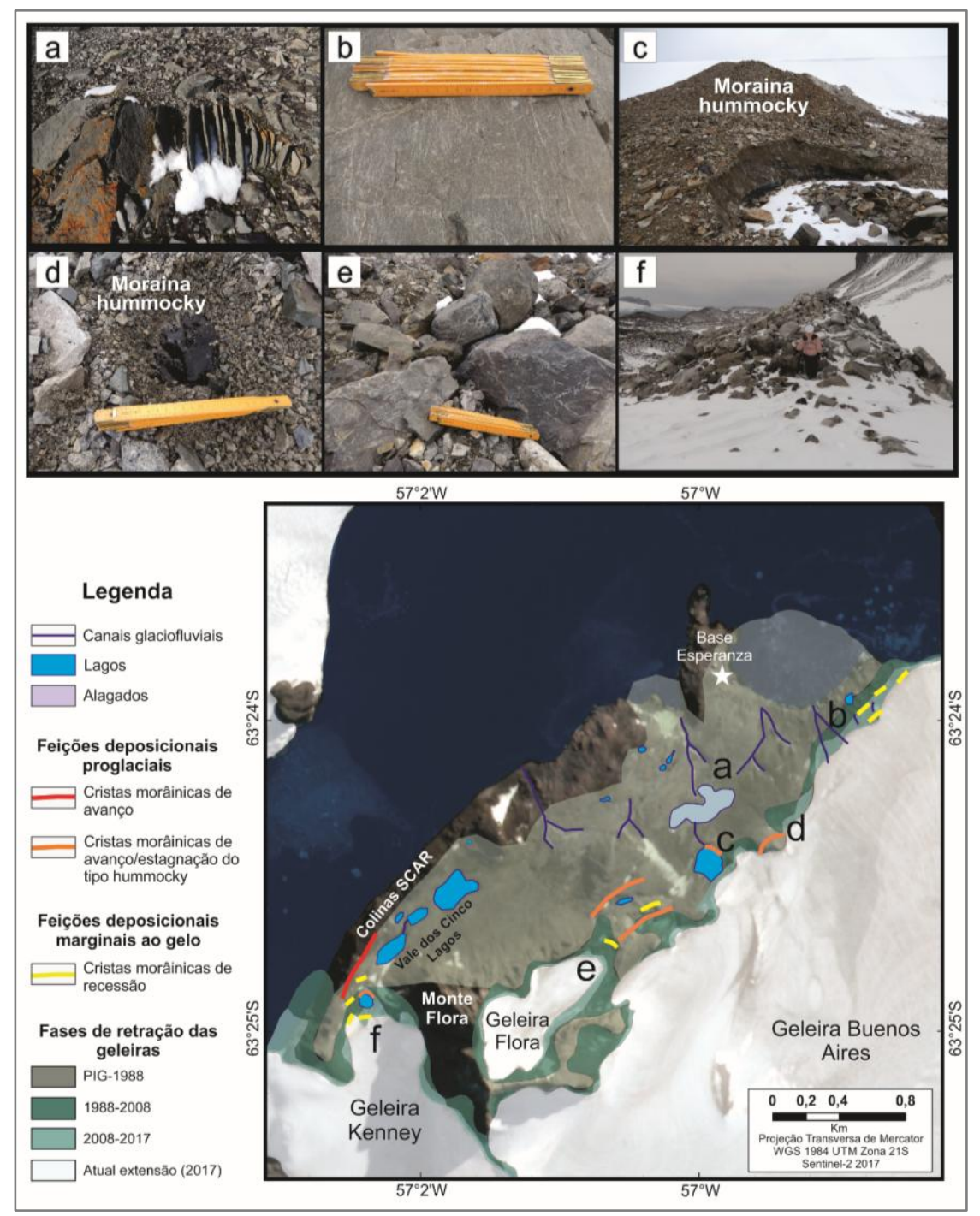

Figura 5: Mapeamento geomorfológico e cronológico proglacial das geleiras Buenos Aires, Kenney e Flora: $\boldsymbol{a}$ - intemperismo físico; $\boldsymbol{b}$ - pavimento estriado; $\boldsymbol{c}$ - moraina hummocky; $\boldsymbol{d}$ - moraina hummocky; $\boldsymbol{e}$ blocos do tamanho de matacão; $f$ - material acumulado na frente da geleira Kenney e proveniente do monte Flora. 
A geleira Kenney possui um ambiente proglacial com presença de água de degelo (Figura 6-3), formação cinco lagos proglaciais e uma sequência de morainas que indicam avanço e recessão. Provavelmente ela se encaixava entre as colinas SCAR e a base do Monte Flora deixando uma moraina de avanço do tipo laterofrontal (Figura 6-3), representada pela amostra 10. Os lagos (Figura 6-3) estão na zona proglacial distal conectados a geleira somente por canais glaciofluviais. No ambiente marginal ao gelo há morainas com 5-10 $\mathrm{m}$ de altura média, com material pouco retrabalhado e cobertura superficial formada quase totalmente por grandes blocos rochosos, provenientes de queda do Monte Flora (Figura 5-F). A moraina hummocky (amostra 9) indica a estagnação/recessão, com uma parte de gelo estagnado em direção ao lago proglacial.

As geleiras Buenos Aires, Flora e Kenney apresentam morainas de recessão condicionadas a sazonalidade com altura máxima de $4 \mathrm{~m}$ e comprimento médio de $6 \mathrm{~m}$, localizadas em ambiente marginal ao gelo e formadas por processos de empurrão e compressão com diminuição da espessura em setores frontais com estagnação/retração do fluxo de gelo. As morainas hummocky se localizam na margem latero-frontal das geleiras Buenos Aires e Flora demarcando, como já discutido, a margem ativa dessas geleiras (Figura 6).

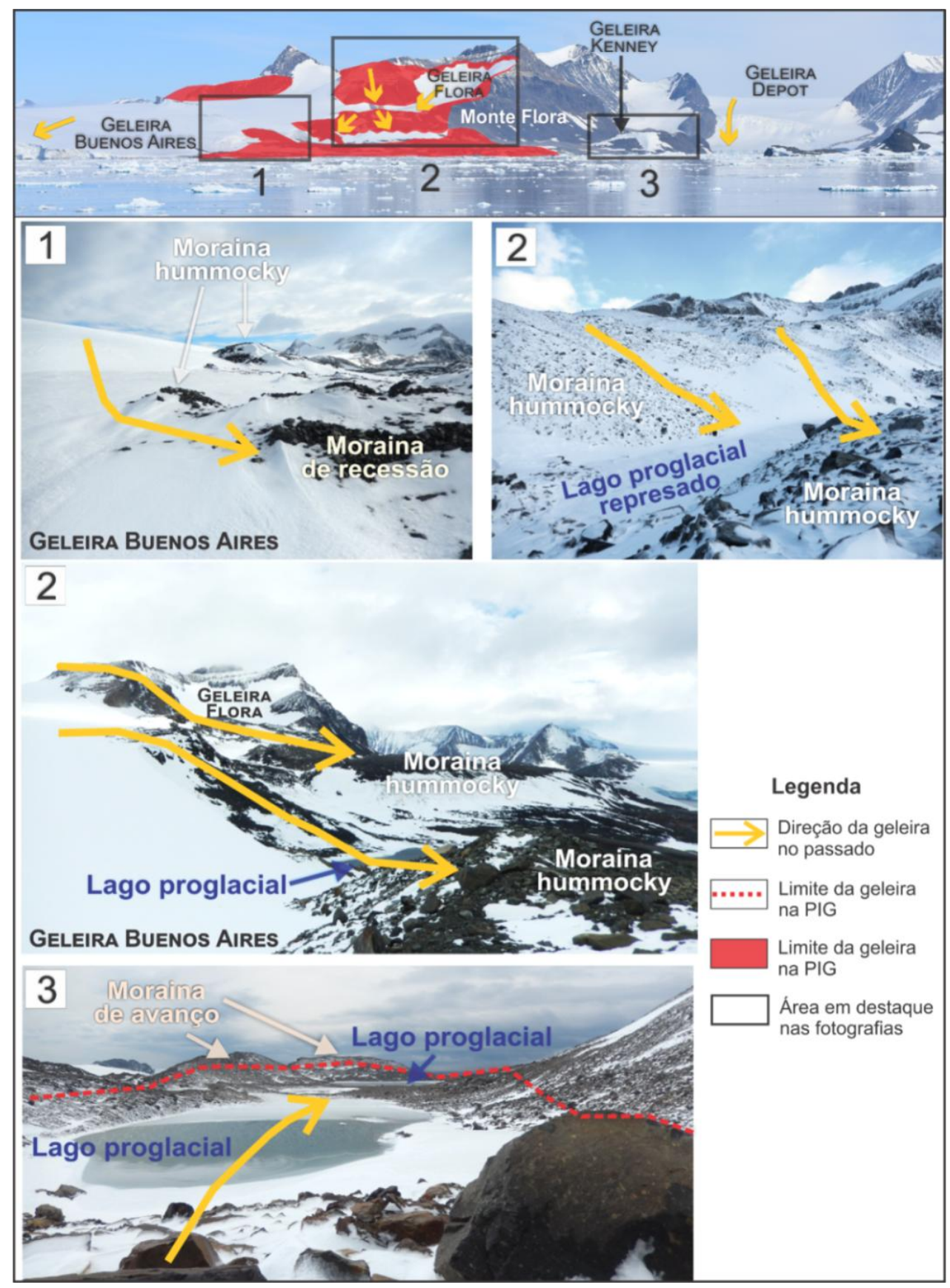

Figura 6: Frente da geleira Buenos Aires, com morainas de recessão recente (1); Área latero-frontal das geleiras Flora e Buenos Aires, com representação de avanços das geleiras durante a PIG (2); Retração da geleira Kenney e lagos proglaciais como testemunhos da frente da geleira (3). 


\section{Discussões}

O predomínio de grãos grosseiros, o baixo selecionamento, os altos valores do índice $\mathrm{C}_{40}$, a predominância do arredondamento em angular e subangular e da textura superficial em sacaróide fosca e mamelonada fosca, são características sedimentares que indicam modificação por processos erosivos em ambiente supraglacial e/ou pouca distância de transporte após o arrancamento do substrato e fraturamento dos grãos por intemperismo físico pós-deposicional.

A reconstrução da evolução do ambiente proglacial e a cronologia das formas deposicionais foram obtidas com o mapeamento das posições frontais das geleiras Flora, Buenos Aires e Kenney desde 1988. Evidenciou-se a presença de lagos proglaciais, pavimento estriado e diferentes tipos de morainas, as quais são importantes indicadoras paleoambientais (KIRKBRIDE e WINKLER, 2012).

A formação das morainas hummocky na parte latero-frontal da geleira Buenos Aires e na parte frontal da geleira Kenney pode estar associada a processos de empurrão de sedimento basal com deposição irregular de till de alojamento (HAMBREY e HUDDART, 1995; SWINZOW, 1962; MENZIES, 1982) ou sedimentos englaciais empilhados na margem da geleira ativa (HAMBREY et al. 1997; BENNETT 2001). Posteriormente, com a recessão da geleira, a exposição da moraina é o resultado da recessão da frente da geleira encaixada no vale (HAMBREY et al. 1997).

A crista morâinica de avanço e o pavimento estriado poderão estar associados à formação durante avanço glacial na PIG. Além disso, a presença de pavimento estriado exposto na área livre de gelo indica a base úmida da geleira Buenos Aires. Benn e Evans (2010) relacionam as feições estriadas com o deslizamento basal e sedimentos subglaciais presentes em uma geleira de base termal úmida.

Provavelmente a partir desse avanço as geleiras Buenos Aires, Flora e Kenney entraram num processo de retração, sendo que há várias áreas proglaciais que ainda estão apresentando processos paraglaciais e uma paisagem mais instável. Além disso, esse processo de recessão progressivo é indicado pelo mapeamento de morainas de recessão, formadas ao longo das últimas décadas.

A identificação da frente das geleiras pode ser prejudicada pela presença de morainas hummocky com núcleos de gelo (ice-cored). Os limites mapeados por sensoriamento remoto podem estar indicando a margem frontal aparente da geleira, já que a "real" borda desta pode estar relacionada ao limite mais distal, coberto pelo conjunto de sedimentos das morainas hummocky, assim como denota Fitzsimons (1990). Se a moraina hummocky está separada da geleira, ela é descrita como estagnada. Porém como as geleiras antárticas se movimentam lentamente é difícil ter certeza se as morainas realmente estão estagnadas (FITZSIMONS, 1990).

Petsch (2018) e Rosa (2008) encontraram nas ilhas Shetland do Sul feições como morainas de recessão recentes e morainas de avanço com morfologia espacial e características granulométricas e morfoscópicas similares às identificadas na Baía Esperança. Contudo, se evidencia um processo mais acelerado de intemperismo para o till das morainas de avanço nas Shetlands do Sul devido a maior presença de água líquida no sistema, proveniente de derretimento da geleira (BRAUN et al. 2001) ou precipitação líquida (TURNER et al. 1997).

A intensa atividade de retrabalhamento pela ação do vento, água de degelo e movimento de massa nos depósitos morainicos provoca mudanças constantes no sistema proglacial. O permafrost perto da superfície gera uma forte erosão crioclástica, com gelifracção ativa e geral em diferentes litologias (arenito, vulcânico e conglomerado) (SCHAEFER et al. 2015), assim, a ação crioclástica também e relevante na área. Comparando com outras áreas onde também ocorreram mudanças ambientais desde a PIG, como nas ilhas Shetland do Sul (PETSCH, 2018; ROSA, 2008), o ambiente da Baía Esperança não apresenta a ação de erosão por canais glaciofluviais e é condicionado à erosão crioclástica (Figura 6-1) (SCHAEFER et al. 2015). Foram encontrados canais glaciofluviais relacionados ao aporte de água de degelo sazonal nival e glacial. Os resultados não indicaram a presença de canais de água de degelo abastecidas por fluxo subglacial.

\section{Considerações Finais}

De forma geral, o processo de intemperismo físico é acentuado, com predominância de material anguloso com arrancamento de material do substrato rochoso e das bases do Monte Flora, e assim, com pouco tempo de transporte. A reconstrução da paisagem holocênica da Baía Esperança indica geleiras com dezenas de metros de avanço em relação à frente atual.

O mapeamento geomorfológico e as análises realizadas evidenciam mudanças ambientais recentes no sistema proglacial. A linha de morainas de avanço mais externa poderá estar associada às morainas de 
empurrão formadas durante avanço glacial na PIG. A parte mais complexa da área se encontra na frente da geleira Flora e latero-frontal da Buenos Aires porque há morainas hummocky que podem evidenciar tanto avanço como estagnação do fluxo de gelo em uma extensa área. Essas morainas podem possuir núcleos de gelo e não evidenciar a atual margem frontal da geleira. O monitoramento destas é relevante, pois estão relacionadas com a formação de lagos represados entre essas feições. As morainas de recessão indicam que a área proglacial teve aumento progressivo com a retração contínuo nas últimas décadas.

Análises de imagens de satélite de maior resolução espacial e o uso de Modelo Digital de Elevação de alta resolução vertical e espacial poderão revelar feições geomorfológicas de meso e micro-escala não mapeadas. Há cristas morâinicas de recessão descontínuas espacialmente, por isto, a atividade paraglacial precisa ser melhor investigada a partir de observações em campo e análises sedimentares.

\section{Referências}

BENN, D. I.; BALLANTYNE, C. K. Reconstructing the transport history of glaciogenic sediments: a new approach based on the covariance of clast form indices. Sedimentary Geology, n. 91, p. 215-227, 1994.

BENN, D.I.; EVANS, D. J. A. Glaciers and Glaciation. Londres: Arnold, 734 p., 2010.

BENNETT, M. R. The morphology, structural 21 evolution and significance of push moraines. EarthScience Reviews, n. 53, 197-236, 2001.

BENNETT M. R.; GLASSER, N. F. Glacial Geology - Ice Sheets and Landforms. Inglaterra: John Wiley, 364 p., 1996.

BIGARELLA, J. J. Contribuição ao estudo da planície litorânea do Estado do Paraná.Arquivos Biologia Tecnologia, v. 1, p. 75-111, 1946.

BIRKENMAJER, K. Geology of late Mesozoic magmatic rocks of Hope Bay, Trinity Peninsula (West Antarctica). Bull. Pol. Acad. Sci. Earth Sci. v. 41, p. 49-62, 1993.

BOULTON, G. S. The development of a complex supraglacial moraine at the margin of Sørbreen, Ny Friesland, Vestspitsbergen. Journal of Glaciology, n. 6, p. 717-735, 1967.

BRAUN, M.; SAURER, H.; SIMÕES, J. C.; VOGT, S.; GOSSMANN, H. The influence of large scale atmospheric circulation on surface energy balance and ablation on King George Island, Antarctica. International Journal of Climatolology, v. 21, n.1, p. 21-36, 2001.

CUfFEY, K. M.; PATERSON, W. S. B. The Physics of Glaciers. $4^{\text {a }}$ ed. Oxford: Pergamon/Elsevier Science, 380 p., 2014.

DEL VALLE, R. A., MORELlI, J. R.; RINALDI, C. A. Geology of new localities on Tabarin Peninsula, Northern Antarctic Peninsula. Antarctic Science, n. 13, p. 323-328, 2001.

FITZSIMONS, S. J. Ice-marginal Depositional Processes In A Polar Maritime Environment, Vestfold Hills, Antarctica. Journal of Glaciology, v. 36, p. 279-286, 1990.

GLASSER, N. F.; HAMBREY, M. J.; Sedimentary facies and landform genesis at a temperate outlet glacier: Soler Glacier, North Patagonian Icefield. Sedimentology, v. 49, n. 1, p. 43-64, 2002.

GLASSER, N.F.; JANSSON, K.N.; HARRISON, S.; RIVERA, A. Geomorphological evidence for variations of the North Patagonian Icefield during the Holocene. Geomorphology, v. 71, n. 3-4, p. 263-277, 2005.

GUSTAVSSON, M.; KOLSTRUP, E.; SEIJMONSBERGEN, A. C. A new symbol-and-GIS based detailed geomorphological mapping system: renewal of a scientific discipline for understanding landscape development. Geomorphology, v. 77, n. 1-2, p. 90-111, 2006.

GOUDIE, A. S.; KALVODA, J. Recent geomorphological processes in the Nagar region, Hunza Karakoram. Acta Univ. Carol. Geogra., XXXIX, p. 135-148, 2004.

HAMBREY, M. J., HUDDART, D., BENNETT, M. R. AND GLASSER, N. F. Genesis of hummocky morainese $^{\text {ee }}$ by thrusting of glacier ice: evidence from Svalbard and Britain. Journal of the Geological Society of London, n. 154, p. 623-632, 1997.

HAMBREY, M. J.; HUDDART, T. Englacial and proglacial glaciotectonic processes at the snout of a thermally complex glacier in Svalbard. Journal of Quaternary Science, n. 10, p. 313-326, 1995. 
HUBBARD, B.; GLASSER, N. Field Techniques in Glaciology and Glacial geomorphology. West Sussex: John Wiley, 400 p., 2005.

KIRKBRIDE, M.P.; WINKLER, S. Correlation of Late Quaternary moraines: impact of climate variability, glacier response, and chronological resolution. Quaternary Science Reviews, n. 46, p. 1-29, 2012.

KRUMBEIN, W. C. Measurement and geological significance of shape and roundness of sedimentary particles. Journal of Sedimentary Petrology, v. 11, p. 64-72, 1941.

LEWIS, D. W.; MCCONCHIE, D. Analyticalsedimentology. New York: Chapman e Hall, 197p, 1994.

OVSTEDAL, D. O.; LEWIS-SMITH, R. I. Lichens of Antarctica and South Georgia: guide to their identification and ecology. Cambridge: Cambridge University Press. 2001

PEREIRA, T.T.C.; SCHAEFER, C.E.G.R.; KER, J. C.; ALMEIDA, C.C.; ALMEIDA, I. C.C.; PEREIRA, A. B. Genesis, mineralogy and ecological significance of ornithogenic soils from a semi-desert polar landscape at Hope Bay, Antarctic Peninsula. Geoderma, n. 209-210, p. 98-109, 2013.

PETSCH, C. Evolução Hidro-Geomorfológica da Zona Proglacial da Geleira Collins, Ilha Rei George, Antártica. Porto Alegre: Universidade Federal do Rio Grande do Sul, Tese de Doutorado, Programa de PósGraduação em Geografia, 2018.

ROSA, K. K. Formas e processos dos ambientes de deglaciação das geleiras Wanda e Ecology, Ilha Rei George, Antártica. Porto Alegre: Universidade Federal do Rio Grande do Sul, Dissertação de mestrado, 2008 .

SCHAEFER, C. E. G. R.; PEREIRA, T. T. C.; KER, J. C.; ALMEIDA, I. C. C.; SIMAS, F. N. B.; OLIVEIRA, F. B.; CÔRREA, G. R.; VIEIRA, G. Soils and Landforms at Hope Bay, Antarctic Peninsula: Formation, Classification, Distribution, and Relationships. Soil Sci. Soc. Am. J. v. 79, p. 175-184, 2015.

SMITH, M. J.; CLARK, C. D. Methods for the visualisation of digital elevation models for landform mapping. Earth Surface Processes and Landforms, v. 30, n. 7, p.885-900, 2005.

SWINZOW G.K. Investigation of shear zones in the ice sheet margin, Thule area, Greenland. Journal of Glaciology, n. 4, p. 215-229, 1962.

TURNER, J.; COLWELL, S. R.; HARANGOZO, S. A. Variability of precipitation over the coastal western Antarctic Peninsula from synoptic observations. Journal of Geophysical Research, n. 102, p. 1399914007, 1997.

WENTWORTH, C. K. A scale of grade and class terms for clastic sediments. Journal of Geology, v. 3, p. 377-392, 1992. 